\title{
Achieving the Research Goal with Qualitative Methods: Lessons Learned along the Way
}

\author{
E. M. Trauth \\ College of Business Administration \\ Northeastern University \\ Boston, Massachusetts 02115 USA \\ Tel: (617) 373-2759 \\ E-mail:trauth@neu.edu
}

\begin{abstract}
The limitations of exclusive use of quantitative methods for social science research in the information systems field have led to increasing interest in qualitative alternatives. However, qualitative methods present their own challenges. The challenge addressed in this paper is that of keeping the methodology focused on the research goal rather than existing as an end in itself. Three different research projects employing qualitative methodologies carried out in three different countries - the United States, Ireland and The Netherlands - are used to explore some of the issues and lessons learned about the use of qualitative methods in pursuit of the research goal.
\end{abstract}

\section{INTRODUCTION}

As the limitations of quantitative methods for social science research in the information systems field have come to be recognized, increasing attention is being paid to the richness and variety available from the alternative approaches offered by qualitative methods. While qualitative methods address some of these limitations, they are not without their own issues which can impede the research effort. In the interests of contributing to our understanding of the benefits and challenges of qualitative re- 
search, in this paper I address some of the issues which I have faced in employing qualitative methods and in attempting to keep the methodology focused on the research goal. In doing so I draw upon three research projects from which I have extracted the challenges and lessons that are presented here. Because of the belief that the researcher cannot be removed from that which is being studied, I have written this paper in the first person.

\section{THE USES OF QUALITATIVE METHODS}

The issues and lessons that I present in this paper are those I have learned over the course of conducting several field studies that have employed qualitative methods wholly or in part. Before discussing these issues and lessons, I will briefly describe the three research projects and how qualitative methods were employed.

\subsection{The Education of IS Professionals}

In this study, our research team employed qualitative methods in conjunction with quantitative methods to explore recent changes in the IT industry and the ensuing fit between the skills and knowledge needed by industry and the academic preparation of IS professionals. ${ }^{1}$ The role of qualitative methods was to complement quantitative methods. While we used qualitative methods throughout the project, we used them exclusively at the initial and concluding stages of this project. The methods included both face-to-face and telephone interviews, open forums and a series of focus groups. Additionally, the research team was constructed in such a way as to represent a variety of viewpoints on the IS field - professors, IS managers and consultants - so that we could also employ participant observation.

Following the dissemination and analysis of a mailed survey we engaged in member checking with representatives of the group from whom we were collecting data - chief information officers - by presenting our initial findings at forums in which we could collect feedback. Member checking, as explained by Ely et al. (1991) and Lincoln and Guba (1985) is a method of establishing credibility whereby the researchers check interpretations with the people who are being studied. We found member checking to be beneficial in helping us interpret our data. For example, there were times when the quantitative data yielded what appeared to be conflicting results. Through the devices of participant observation and member checking, we received help in deriving possible explanations for these contradictions. One obvious shortcoming of member checking arises when the respondents' and the researchers' interpretations are in conflict. This was not the case in this project, however. Rather, member checking helped to enhance interpretation of the results.

${ }^{1}$ A complete description of this study can be found in Trauth, Farwell and Lee 1993. 


\subsection{Societal Influences and Impacts of an Emerging Information Economy}

In this second study, which is still in process, I am using qualitative methods exclusively and I am the sole investigator. I am examining Ireland's industrial policy of economic development through inward investment by information technology (IT) multinational firms as well as through the development of an indigenous IT sector. My interest is in examining the influence of societal factors on the shape of the IT sector in Ireland as well as the impact of this sector on Irish society. ${ }^{2}$ Because of the scale and duration of this study, most of the examples I use in this paper are from this project.

I am studying the information workplace by means of participant observation of and interviews with IT workers and managers. In conducting this study, I am engaging in participant observation at both the micro and the macro levels (see Jorgensen 1989; Becker and Geer 1969). During the period in which I conducted the interviews with IT workers, I spent considerable time in fourteen IT firms in Ireland. Half of these are multinational (American) firms and half are Irish firms. On these site visits, I was able to observe the work environment, atmosphere and management style, all of which I was also discussing with the respondents during our interviews. This was the micro level of participant observation.

In order to place the information obtained from these interviews in a larger context, I also collected information about Irish culture, society, economy and public policy. I did so by means of participant observation, ${ }^{3}$ interviews, and documentary analysis. At this macro level of participant observation, living and working in Ireland and communicating with Irish people enabled me to observe and directly experience Irish culture and to compare this information with what I was hearing in my interviews. Through subsequent time spent in Ireland, I have continued to observe Irish culture and society. ${ }^{4}$ Additional relevant information about Ireland has been obtained from interviews with those outside the IT sector, public policy documents and social commentary found in Irish newspapers, magazines and books about Irish society,

${ }^{2}$ This study in its early stages was the subject matter of a paper presented at the 1990 IFIP Working Group 8.2 Conference on Research Methods (Trauth and O'Connor 1991). Descriptions of specific aspects of this study can be found in three additional papers by Trauth (1993, 1995, 1996b).

${ }^{3}$ During the first year of this research project in which the interviews with IT workers were conducted, I lived and taught in Ireland.

${ }^{4}$ As will be explained in more detail later, data collection is still going on through my return visits to Ireland and ongoing communication with selected informants. Thus participant observation is still occurring. 
history and culture. This information has been used in determining which societal factors to explore in my interviews, to refine the coding categories and subcategories and to put into a broader perspective what I learned from my interviews. ${ }^{5}$

\subsection{Influence of Societal Factors on the Diffusion of Information Technology}

The third application of qualitative methodology was an exploration of the influencing role of societal factors in the diffusion of a new technology. The setting for this study was The Netherlands and the particular information technology was electronic data interchange (EDI) (Trauth, Derksen and Mevissen 1993). The purpose was to learn about the roles that public policy, national economy, culture and societal infrastructure can play in enhancing or inhibiting the organizational adoption of this particular information technology.

Our research team ${ }^{6}$ used the qualitative methods of open-ended interview, participant observation and documentary analysis. The respondents in our study included technology vendors, corporate users, policy makers, and researchers and consultants who have worked on EDI implementations. I participated in each of the semi-structured interviews accompanied by one of my two coinvestigators.

\section{METHODOLOGICAL CHALLENGES AND LESSONS LEARNED}

In this section, I draw upon these three research projects to share some of the lessons learned during the actual application of qualitative methodologies. These lessons derive from the methodological challenges I encountered over the course of the projects. It is these challenges which I would like to address in this section. Content analysis of research journals which I maintained during the projects ${ }^{7}$ revealed the presence of several methodological themes which emerged from my own research. The issues embedded in these themes arose throughout all phases of the research projects from model creation to data collection to data analysis to presentation of

${ }^{5}$ For example, in analyzing my data on women in the IT sector, I used documentary analysis to compare my findings with those of Irish researchers working in the area of IT and gender. I found that my conclusions concurred with those of one of the researchers and diverged from those of the other (see Harris 1989; Jackson and Barry 1989).

${ }^{6}$ The other two members of the team are Dutch.

${ }^{7}$ I did not maintain a research journal while conducting the study of the education of IS professionals. However, I did compile extensive notes on each phase of the data collection, both qualitative and quantitative, and noted issues that I encountered along the way. 
results. To the extent that they are generalizable to other contexts, they can provide useful guidelines for those conducting similar research. The challenges can be conceptually organized around three themes: objectivity, flexibility and linearity. Within each are the lessons I have learned along the way.

\subsection{Objectivity}

This theme is about how my own training in positivist thinking and quantitative methodologies has served as an obstacle to my work. My own education taught me that objectivity is the hallmark of good science, that standing apart and conducting consistent measurements is the proper way to ensure validity. A dilemma I faced in these research projects was how to cope with the subjectivity that is an inherent part of qualitative methods. Part of this challenge was learning to be comfortable in my dual role. On the one hand, I needed to fully participate in my context in order to collect and interpret information. Yet $I$ also felt the need to remain apart from this context in order to be able to note and process what I was experiencing and learning. I felt the need to maintain some psychic space around myself for reflection and analysis. It has been referred to in the literature of ethnography as staying strange (Hammersley and Atkinson 1983). ${ }^{8}$

\section{Lesson 1: Becoming "Self Conscious" and Questioning Assumptions}

In the case of the Irish study,I was an outsider to the culture who was collecting data for a limited period of time. Therefore, I was not able to identify or fully understand all the cultural nuances I was experiencing. Consequently, I have had to develop mechanisms for compensating in some way. To do this, I have sought alternative viewpoints on both the factors under study and on my interpretations. In this way I am seeking to evaluate both the data collected and the resulting interpretations and conclusions.

Additionally, remembering that the presence of the researcher influences the data collection, I sometimes wondered about the extent to which the respondents were simply telling me during interviews what they thought I wanted to hear. I wondered about the extent to which they were "packaging" their responses to me. I wondered how much I could believe what they were telling me. My response to this reliability issue has been to rely upon the consistency of responses across respondents and triangulation in order to ensure multiple perspectives on each topic (Jick 1979).

One source of alternative viewpoints on the phenomenon came through my social network. I found myself turning to various Irish and American friends and colleagues as a sounding board for the cultural factors I was identifying and exploring. Even though - or perhaps especially because - these individuals tended not to work in the IT sector, they were able to provide different perspectives than those offered by

${ }^{8}$ I will return to the controversy about this notion in the Epilogue. 
respondents or from those I was developing. When it came time to interpret and present the results of my analysis, once again I have relied upon a form of member checking. I have had informal conversations and have sought feedback on paper drafts from colleagues in Ireland and in the Irish studies community in the US.

A related issue is the need to constantly question myself as a source of data, to question my own assumptions. This heightened sensitivity to context helped me to develop of posture of being "self conscious," to use the words of a British respondent who was working at an American firm in the west of Ireland. He said that he is self conscious in the sense that he reflects on his reactions. Since he had only recently come to the Republic from Northern Ireland he was very attuned to the cultural experiences I was having. Indeed, several times throughout my visit at his firm he would stop by my interview room to share his thoughts with me.

Halfway through my research year in Ireland, I was asked to give a research seminar at the university where I taught. I reluctantly agreed. My hesitation was that I had just begun to conduct my interviews and felt that I had little by way of valuable conclusions or insights to offer. The experience impressed upon me the importance of questioning my own assumptions. The first assumption to be questioned was that giving a seminar would be a one-way communication event. Instead, the experience became an opportunity for me to articulate some of my assumptions and initial perceptions and to receive feedback on them. While the audience of Irish faculty and students was not hostile, neither was it overly supportive of what I was doing. ${ }^{9}$ It was not until they learned more about the thrust of my research, that they began to set aside their own assumption that the purpose of my research was to glamorize the presence of American multinational firms in Ireland. Their challenging questions influenced me to question what I was thinking and assuming and perceiving as much as I may have influenced them.

In the case of my research in The Netherlands, I did not have the same issues to overcome. My task was easier in some respects and more challenging in others. For several reasons I remained more in the outsider role. Since I do not speak Dutch and because I lived in The Netherlands for a shorter period of time than I did in Ireland, I was not as acclimated into the Dutch culture as I was in Ireland. In addition, because I was working with two individuals from that culture I could rely more on their perceptions to help me interpret data. On the other hand, I had to be alert to the biases and assumptions they brought to bear on their interpretations. In the IS education project, there were three different cultures represented in the project: the academic, the consulting and the practitioner. Throughout the phases of our research project, we used our different positions in the IS field to challenge each others' assumptions, interpretations and conclusions.

\footnotetext{
${ }^{9}$ At the time, there was an antimultinational sentiment in some quarters of Irish society and this viewpoint was represented in the audience in attendance at my seminar.
} 


\section{Lesson 2: Getting Close to People}

Early on in my year in Ireland, I noted in my journal concern that I was perhaps enjoying myself too much and wondered whether I was staying distant (aloof was how I termed it) enough during the interview process. As the year wore on, I became more comfortable with the idea of enjoying myself during my research and even becoming friendly with some of the respondents in my study. However, as I became more comfortable with the people and the country, I continued to be aware of the issue of just how familiar I should become.

One respondent - an American woman - observed that the sense of familiarity can be deceptive. She pointed to the absence of markers of cultural difference (such as race or language) that signal foreignness. Hence, while I may have become more comfortable with Ireland and Irish people, they may not have felt the same toward me. One Irish respondent with whom I spoke toward the end of my year told me that there probably was a period of assessment during which colleagues and acquaintances were checking my values to see if they fit with theirs, observing how I reacted in certain situations, and identifying my personality traits to see if they were acceptable.

During the last month of my stay in Ireland, I had two occasions on which I wondered if $I$ had crossed the line and become too familiar in my surroundings. In both instances, I had engaged in a lively discussion in which I exchanged views about such charged topics as gender, contraception, abortion and religion with individuals with whom I had spent a fair amount of time over the course of the year. In noting their reactions to my views when we differed, I was brought back once again to the issue of balancing distance and familiarity. I concluded that achieving the proper balance has both ethical and methodological dimensions.

When I reflected upon my experience of interacting with people whose views were different from mine, I noted that when these others controlled the flow of information, when I was primarily a passive listener, our interactions were fine. As I became more comfortable with these people and began to open up and share more of my own personality with them, I felt a tension develop. As I was becoming closer to these people as friends, I wanted to reveal more of myself to them. In reflecting on these two situations, I wondered (methodologically) whether I had been too much my own person and not enough the researcher, and as a result, was running the risk of alienating these informants. But I also wondered (ethically) whether it was proper to be so much the researcher in my interactions that these aspects of my persona had not emerged sooner.

\subsection{Flexibility}

Two months into my year in Ireland, I noted in my research journal that I felt I was moving about aimlessly and had yet to establish a coherent research design. I expressed discomfort about my research process that seemed to be out of control. I recorded similar sentiments at the early stages of my Dutch research. The important 
lesson I learned is that, when using qualitative methods, the more alien the context, the more important flexibility becomes. I learned that the researcher has to be prepared to embrace the data when it is presented regardless of the location, intention or source.

\section{Lesson 3: Giving Up Control}

In the Irish project, one example of not controlling the time or location of research occurred through my encounters with a couple of Irish families who befriended me. I was frequently invited to their houses for a Sunday afternoon. When I would arrive, I never quite knew what new things about Ireland I would learn or how I would be learning them. I just began to expect the unexpected. I had similar experiences in The Netherlands. Since my study of the diffusion of EDI involved examining aspects of Dutch society, relevant data was obtained during a weekend outing or during a conversation in the cafe after work or in the middle of work on another project.

Another time that I had to cope with not being in control was during my on-site interviews in Ireland. My initial reaction when I found that there were questions I did not get to ask was to wonder if I should perhaps establish a priority among my list of items and adhere rigidly to it. Alternatively, I thought perhaps I should just be more flexible and allow the flow of the discussion to guide me. I gradually developed a comfort level with doing the latter. Entries in my Irish research journal throughout the interview process registered concern about wanting to control the interview process, to make certain I was covering all the topics during each interview. I was feeling obsessed about the methodology. What I was struggling with was the acknowledgment that - contrary to what I may have been taught or how research projects are written up for publication - the qualitative data collection process was not something over which I had complete control. I would need to go back and reassess the data over and over again. If I tried to control the responses too much, I would perhaps get data I sought but I would not have the information I needed. I would be missing the opportunity to gain unplanned insights. Indeed, several cultural factors that became part of my study were initially introduced by the respondents themselves. ${ }^{10}$

Allowing the respondent rather than the interview protocol to drive the discussion was very useful particularly before I had a complete list of the societal factors I wanted to study. I had to remind myself that the number of respondents - eighty-five - ensured that in totality all of the topics would be covered, that consistency would assert itself in the end. However, at times I had to resist the urge to have breadth of treatment at the expense of depth. I sometimes had to fight against the urge to cover all the topics superficially rather than fewer topics in greater depth.

${ }^{10}$ Examples are "This is Ireland," social class, island mentality, British management style, attitude toward time, the family. 
Since I was able to apply to my research in The Netherlands the methodological lessons I was learning in Ireland, ${ }^{11} \mathrm{I}$ had less anxiety about consistency across each respondent. In fact, covering all the items in the interview protocol during the Dutch interviews was more the exception than the norm!

\section{Lesson 4: Always Working}

By giving up control over the circumstances of data collection, I soon recognized that I was always working. In one entry in my Irish research journal, I noted that during a dinner party I had obtained valuable background information about a particular firm I wanted to include in my study. In wishing that I had brought along my tape recorder, I was recognizing that my research goes on continuously. I noted that I had to become more prepared to take advantage of all opportunities to learn more about what I was studying.

For example, during one of my early on-site interviews, the Irish human resources manager at one of the American firms was stiff and formal during our conversation in his office. I had difficulty during the interview getting him to open up about his cultural impressions. He seemed to want to stick with official law and policy. At the end of the conversation, over coffee in the canteen, he loosened up considerably. (I was also not taking notes.) After being very careful about his cultural commentary in his office, in the canteen he proceeded to share a variety of impressions about Irish culture and even went so far as to provide cultural commentary about people in other European countries! This particular experience sent a strong message to me that I did not control where or when the "research" would occur and that I needed to be ready to seize the opportunity when it arose.

The reality of always working means that a conversation in a restaurant or a pub, cafe or dinner party is quite often a source of research data. One day, an Irish faculty colleague invited me to join her and a guest speaker in her class at the local pub. Her guest speaker is an Irish film maker and I was invited not because of my research project but simply because I was friendly with this colleague. As it turned out, this man was able to offer me considerable cultural insights that were quite valuable to my research.

In The Netherlands, I had the experience of finding useful information for my EDI study while I was engaged in other work. One time I was invited to give a presentation at another Dutch university on some research I had done on a totally different topic. During conversation with the faculty members afterward, I learned that one of their colleagues could provide very valuable information regarding our research project. Eventually, this person was added to our set of respondents.

An extension of always working is taking advantage of social networks both to find contacts for interviews and for purposes of cultural observations. In Ireland, one rich

\footnotetext{
${ }^{11} \mathrm{I}$ began the research in Ireland in 1989 and undertook the research in The Netherlands in 1992.
} 
source of research contacts happened quite unexpectedly through my participation in the American Women's Club. This organization is comprised of two types of women. One type is the wife of a multinational executive. These women tend to be in Ireland three to five years while their husbands are setting up the subsidiary of an American IT firm in Ireland. The other type of woman is married to an Irish man and lives permanently in Ireland. The initial contact at several of the firms at which I conducted interviews occurred at social functions of this organization. The Irish people I met through dinner parties and other social functions were a rich source of cultural commentary and counterpoint to my developing impressions. In The Netherlands, my position on the faculty of a university helped me to identify respondents. Several recommendations about respondents came from faculty colleagues or others at the university where I taught.

\section{Lesson 5: Collecting both Data and Metadata}

Early into my round of interviews at the IT firms in Ireland, I had an experience which pointed out the importance of having sensitivity to contextual metadata. In reflecting on an interview with an Irish worker at an American plant, I noted that I had to be vigilant in order to be able to respond to the exigencies of the particular context I was in at any given moment. In this particular situation, the respondent was - at age forty-eight - the oldest worker at the plant. He was nervous upon first meeting me. As the human resource manager introduced me and briefly explained my research project, the man stood there shifting his weight from one leg to the other, pulling out of the back pocket of his jeans and fumbling with a rolled up copy of the three page summary of my research project which I had sent to the managing director. As I watched this man, I tried to put myself in his place. He had been made redundant three times already and had only been at this particular firm a matter of months. Now here he is, being asked by senior (American) management to talk with this American woman! A quick assessment of the situation led me to decide not to even ask if I could use a tape recorder, something I normally did at the beginning of each interview.

A similar situation which called for heightened sensitivity to context occurred at another American firm. This firm was experiencing financial difficulties and redundancies were a distinct possibility. In both my collection and interpretation of data from this firm, it was important for me to recognize that this atmosphere of diminished resources and layoffs was generating considerable insecurity which could, in turn, influence respondents' perceptions and be reflected in answers given during the interviews.

Perhaps the most poignant experience that I had with data and metadata was the interaction that I had with several female respondents. The type of interaction I had with several of the women whom I interviewed was both a surprise and a puzzlement. As a rule, I found the interviews with female respondents more difficult than those with males. Some women were merely abrupt and not inclined to be introspective about cultural factors. A few bordered on resistant. One woman bristled in the course 
of my collecting background demographic data when I asked what part of Ireland she was from: "I thought this wasn't going to be anything personal!" she replied. I was aware of working extremely hard to get her to open up to me. I believed myself to be successful when she began to smile part way through the interview. By the end, she said maybe she would be in Boston some day and I could sign a copy of the book I was going to write. Another woman kept me waiting quite a while beyond the agreed upon interview time of five o'clock. When I was finally escorted into her office, she looked at her watch and informed me that she could only spare thirty minutes (after both she and her boss agreed beforehand that we could talk for ninety). Through all of these interactions, I came to recognize that observing the respondent and the context during the interview process provided a rich source of metadata to accompany the data I was collecting.

\subsection{Linearity}

This last theme encompasses issues that speak to the way in which the methods are applied. The challenges associated with linearity are about letting the research flow naturally, as it needs to in pursuit of the research goal. They are about letting the research goal determine the way in which the research is conducted. While this may seem like a fairly obvious point, I encountered several temptations and pressures grounded in "conventional" scholarship to do otherwise. This theme contains lessons for definition of scope, sources of data and identification of respondents, data collection and analysis procedures, and coding schemes.

\section{Lesson 6: Fitting the Method to the Model}

The research project I conducted in Ireland was one that I had waited several years to undertake. From the beginning, I was very clear about the research goal - to depict and analyze the emerging information economy in Ireland - even if I wasn't completely sure how I would go about reaching it. As I was working to develop my research model to fit that goal, I encountered well-meaning suggestions to do something different. This advice seemed to be driven more by methodological convenience than by a desire to help me further the research objective I had in mind.

According to Yin (1989), a case study is an empirical inquiry that investigates a contemporary phenomenon within its real-life context, when the boundaries between phenomenon and context are not clearly evident and when multiple sources of evidence are used. My project fit this definition in that I intended to use on-site interview and observational data as well as internal and published documents. Unlike typical business case studies, however, in which a single company is the object of study, the scope of my case study was to be much larger in that it would be an industry-level case. In addition, I would be employing ethnographic techniques. However, since conventional IS case research is conducted with the unit of analysis being a company, conventional wisdom (and scholarship) was directing me toward that end. This occurred in the form of well-meaning advice given to me as I was trying to develop 
my research model. Rather than try to help me develop the methodology that would enable me to achieve the research goal that was of interest to me, I was advised to pursue other research goals in the interest of methodological ease. In one instance, I was asked to change the title of a paper I had written because a reviewer claimed my scope was too large to be considered a case study.

I do not believe I would have been able to obtain the rich viewpoints that I have received had I used the smaller scope of a single firm case study. When I explained to colleagues that my interest was the IT sector as a whole, not a single company within it, I was advised to send a mailed questionnaire to a large number of firms. Although this option is one way of addressing the scope aspect of my research, it would not have furthered my research goal since the set of factors that I wanted to examine needed to be developed in grounded fashion (Strauss 1987). At this point - having identified and documented the societal factors of interest - I could perhaps engage in an in-depth case study of workers at a single IT company and examine those factors in action. If I were interested in a different outcome, I could have conducted a mailed survey of a large number of firms. The picture I wanted to paint, however, required a qualitative approach and a canvas as large as the entire country. In my view, this lesson is especially important because it has implications not only for the conduct of our own research but also how we educate and advise future scholars. The message is to make sure not to get the (methodological) cart before the horse (research goal).

\section{Lesson 7: Beginning at the Beginning}

Early in my career, I had a conversation with a more senior colleague about a research project I had in mind that had to do with studying the relationship between information policy at the national level and corporate policy. He began to quiz me about how I would measure the "relevant variables." When I told him that I didn't think I knew how to think about his project in terms of measurable variables, he replied, "Well, then you're not yet ready to begin the research."

I had obviously internalized this admonition to some degree because about a third of the way through the year I lived in Ireland I was feeling frustrated with myself that so much time had gone by and I was just then starting my "research." I was thinking that the research would begin when the on-site interviews commenced. I held this view because I defined research as the conduct of the formal interviews. What I came to recognize is that research began the moment I first started to explore my themes. Gradually I became comfortable acknowledging that generating the questions in grounded fashion through participating in and observing the culture was also part of the research.

Some time after returning from my year in Ireland, as I was working on a paper about the IS education project, I received external validation of the lesson I had learned in Ireland. In reviewing our paper, the journal referees suggested that in writing up the results of our survey, we should reorient the paper to include more of 
the initial, qualitative results. Up until this point, we had viewed that work as preliminary or background research only.

Half of the lesson, here, is recognizing that while different phases may require different methods, research begins at the beginning. The other half of the lesson is that the research does not end with the analysis of data. The final piece is returning to the field for contextual validity. The reason for this final stage is that processed data can result in different interpretations. As a researcher, my assumptions, biases and motivations all influence the way in which I make meaning from that processed data. Going back to the context to receive feedback on my interpretations serves to enhance validity. In the case of the IS education project, we conducted structured feedback sessions in order to present our results, give our interpretation of the data, collect feedback on those interpretations and solicit alternative interpretations. In the case of the Irish project, I am employing two mechanisms for collecting this contextual feedback. One has been to present my findings to Irish studies scholars for critical review. The other is circulating drafts of my written work to selected respondents and other individuals for commentary.

\section{Lesson 8: Staying True to the Research Goal}

In the case of all three of these research projects, the identification and selection of respondents for the studies was something I expected to be rather straightforward; it was not. Because of the unexpected nature of the data collection in the Irish study, I not only changed my definition of when research begins or occurs but also who comprised the set of respondents. In the study, some after-the-fact inclusion of respondents occurred when I recognized that while a given exchange may not have been planned, it nevertheless provided insights comparable to those that were. For example, during one of my days spent interviewing at an American firm, a worker who I was not scheduled to interview had been designated by management as my luncheon companion. As we ate, I told her about my project and she, in turn, told me about her background, her work history, and gradually began to offer unsolicited comments on the items I was investigating in my interviews! Similar experiences happened in the Dutch study when casual conversations about electronic commerce or technology diffusion in The Netherlands turned into insightful comments directly relevant to my research project.

Once the on-site corporate interviews in Ireland were completed and I returned to the US for the data analysis phase, I encountered still other challenges to remaining true to my research goal. This new challenge had to do with how I would carry out the content analysis of the data. In considering my options for data analysis, one was to employ software that would search for certain keywords taken from the interview protocol and then retrieve surrounding text. To go that route would have considerably shortened the lengthy process of the alternative - and chosen - method of dividing transcripts into meaningful units or content chunks, creating coding schemes, coding each of these content chunks, and then loading them into a database for retrieval. There are two problems with using the first approach, however. The first is that the 
keyword is not as inclusive as the concept underlying it. For example, one of the themes about which I spoke with respondents is social class. This is an important factor in that social class governs in large part who goes to college to get the credentials to work in the information sector. The problem, however, was that people rarely used the words "social class" when speaking about it. Instead, they would comment indirectly by such means as mentioning a certain part of town as an indicator of social class. In some cases, as in this instance, I was soon able to discern during the interview that they were using code for social class. In other cases I was not. At the beginning of each interview, I collected data about the respondent's background including education. For quite a while I was puzzled by respondents' repeated reference to the particular religious order of nuns or priests who taught them until I learned that a Jesuit school, for example, had higher social standing than one run by the Christian Brothers! Thus, a significant amount of valuable data richness would have been sacrificed had I chosen the keyword route.

Once I had determined to code each content chunk for relevant categories, the next decision was which categories to use. My choice was either to use categories present in the interview protocol or to let the categories evolve from the data. I chose the latter. My rationale was that to do otherwise would be to overlook some of the unintended voices and messages present in my interviews. Maintaining consistency across transcripts when using evolving categories for data analysis, however, became a new challenge throughout the coding process. In the end I was satisfied with the meaning conveyed in the categories and the keywords.

\section{CONCLUSION}

After systematic reflection on my use of qualitative methods in these studies, I cannot say I have derived definitive answers about the rules of proper behavior in every situation. However, I have come to some conclusions which have influenced subsequent research. One is that as a researcher I cannot be removed from the context, nor should I want to be. I cannot be totally outside the setting and yet be successful in my research. In the case of the Irish study, several of the respondents have become close acquaintances; a few have become friends. To generalize from my own experience, I believe the answer is not for the researcher to remain apart from the context but rather to embrace it. At the same time, however, the researcher should constantly be conducting self examination with respect to assumptions, biases and motivations being used to interpret data; should make use of multiple perspectives and sources of data - and be open as to their source; and should obtain feedback while in the process of both collecting the data and interpreting it. Collecting and analyzing the data in this way speaks to the need for an iterative rather than a linear approach to the conduct of the research. This suggests that the neat outline be replaced with an evolving mosaic which is intended to serve the research model, not a predetermined 
methodology. I have learned that these approaches have been necessary if I am to achieve the goal for which the research was undertaken.

The challenge and the reward for letting the research goal drive the methodology is, for me, embodied in the interview experience I had with a young Irish woman who works for an Irish software firm. I first met her at the company site to introduce myself and schedule an interview. First, she wanted to think about my interview questions in advance of meeting with me, so I gave her a copy of the interview form. Then she suggested we meet outside work. I agreed and asked where she would like to meet and when, thinking she would suggest some coffee shop. Instead, she suggested a Dublin pub at six o'clock the following week. She then mentioned the names of three professors at the university where I taught and said they were all left of center in their political views.

As I prepared for my interview with her, I tried to sort through all the metadata contained in that initial conversation. One interpretation was that I was being tested. Perhaps her comments about the left-leaning tendencies of the professors was a test of my willingness and ability to set aside my American-business-professor persona and accommodate to a different setting. Alternatively, the interview-in-a-pub could have been an acknowledgment of my acceptance, given the focal point of pubs in Irish culture. Not knowing for sure, I substituted my normal interview attire for blue jeans, entered the pub and waited with a glass of Guinness in hand for my respondent. She brought along her sister and two young men who had been classmates in university. Then, for the next five and a half hours, I listened while the four of them talked quite frankly about Ireland, the culture, the IT sector and themselves. I ran the tape recorder until the tape ran out. In the semi-light with my Guinness glass constantly being refilled by my respondents, I took notes furiously until my notepaper ran out and I had to resort to writing on the back of my interview form! As I left that pub, I was certain that I had not worked as hard in any other interview, yet it was also one of the most rewarding experiences and clearly one of the richest interviews of the entire research project.

What I expected to learn as a result of my use of qualitative methods in these various research projects was about the subject matter at hand. What I did not expect was the additional learning about methodology and myself. The employment of these methods has been an opportunity for personal growth in helping me to question my assumptions and challenge my approaches. It has made me much more aware of the organic nature of change in general and learning in particular. Above all, I have been reminded that, as a researcher, not only do I not have all the answers, I don't know all the questions either.

\section{EPILOGUE}

As I have pointed out in this paper, one technique I have employed is member checking. With this technique, during the final stages of a research project the researcher shares preliminary insights and conclusions with either the participants in the study or those in a position to provide informed comments. Insofar as this paper represents 
a "research project" about methodology, it seems appropriate to obtain and respond to feedback about it. I would, therefore, like to respond to some of the questions about my methods and how I apply them that have not been completely addressed in the body of this paper. Some of these questions were raised in reviews of this paper; others have come from questions and comments during previous conference presentations. I have organized my responses to these questions around two themes: strangeness and reliability. In many respects, they derive from the same point: the unstable ground of subjectivity.

\subsection{Strangeness}

This theme is about conducting research as a stranger to the culture. It is a highly charged topic that evokes images of colonialism in which the stranger comes from the outside to "do" a foreign culture. I have addressed some of this in Lesson 2. But I would like to respond more fully to the notion of an outsider to the culture under study. To begin, I would like to quote from a paper which I delivered to a community of Irish scholars in 1996.

In looking for some reference in my bookshelves recently, I happened upon a particular copy of a professional journal in my field of business information systems that caught my attention. The article was about the potential for gender-based discriminatory practices in information systems management and was written by two men. As a woman, my first reaction was, "Right! What can these two male authors tell me about gender discrimination in my field? As men, how would they be able to understand and represent the female experience?" Those silent words no sooner left my unmoving lips than I recalled the paper I was planning to write for this Irish studies conference on the topic of crossing cultures. In quick succession, my thoughts turned to an experience I recalled having just a couple of weeks after I had embarked upon a major research project in Ireland.

Full of enthusiasm for my research project, I paid a courtesy call on a professor who was known to one of my Irish studies colleagues in the States whom I was told might be able to help me identify contacts for my research. After I gave a brief overview of my research project, he sat back in his chair, looked at me and said politely yet bluntly, "I don't know what you intend to do that's new. Everything you want to do has been done before." As a teacher I am used to thinking on my feet so I managed to recover from this pinprick to my research bubble. But during the ensuing months as I refined my research thesis and methodology, I was haunted by his remarks. By the time I embarked upon the on-site data collection, I had taken on those words as a personal challenge: to prove that although I was an outsider to the culture, nevertheless, I had something to contribute to the developing story of Ireland's information economy. [Trauth 1996a] 
It seems to me that there are two aspects to the notion of strangeness that must be addressed. One is the justification for one who is not of the culture conducting a study of it. The best justification that I can give is that, in being alien to the culture, I am able to see assumptions and behaviors that might be more difficult for those in the culture to see. If one rejects the viewpoint that those outside the culture or group have no right to study it, then the challenge becomes one of capitalizing upon the strengths of being an outsider while being ever sensitive to the pitfalls of conducting contextual research as a stranger to it. So, having embarked upon a study of another culture, the next issue is whether and how much distance to maintain between myself and what I am studying.

As I have demonstrated throughout this paper, I have made a conscious effort to embrace the contexts in which I was conducting my qualitative research. Yet it is also true that I would never understand that context in the way that an insider would. My response has been to acknowledge this "otherness" and to take advantage of its benefit in helping me to maintain the analytical distance I needed. Hammersley and Atkins have talked about this "strangeness" as the hallmark of good ethnography.

The comfortable sense of being "at home" is a danger signal. ... There must always remain some part held back, some social and intellectual "distance." For it is in the "space" created by this distance that the analytic work of the ethnographer gets done. Without that distance, without such analytic space, the ethnography can be little more than the autobiographical account of a personal conversation. [Hammersley and Atkins 1983, p. 102]

In a later work, Hammersley (1992) acknowledges that, with the movement of ethnography toward relativism in recent years, this requirement for maintaining distance has diminished.

For my own part, I have come to see maintaining some distance as a necessary part of being self aware. This is not to say I did not participate fully in the context I was studying. Rather, to me it means attempting to bring into consciousness the emotional and intellectual reactions to experiences and observations. I interpret - and believe the value of - "strangeness" to be maintaining a psychic space in which I can make myself consciously aware of things that others might take for granted. In rereading methods books about this topic, I saw analogies with therapy, poetry and photography. In all these instances, one is totally "in the moment" yet also retains a space from which to frame the setting and reflect on it consciously in order to understand psychological forces, create a poem or take a photograph. My objective in maintaining strangeness is to engage in introspection while still engaging in routine activities.

\subsection{Reliability}

A second major theme, and one with which anyone doing qualitative research may be confronted, is establishing reliability. To those schooled in positivistic methods, the highest ideal of research is achieved through objective, value-free data collection and 
analysis which subsequent researchers can repeat with consistent results. The subjective nature of qualitative methods, in general, and ethnographic ones, in particular, therefore, calls for a totally different perspective on reliability. First, what does reliability mean in an ethnographic study? To me it means producing results that can be trusted and establishing findings that are meaningful and of interest to the reader. One measure is whether those familiar with the context can recognize in the results their own world of experience, whether the story being told "rings true" to them.

One hurdle I had to overcome in developing a comfort level with qualitative methods was fully accepting the fact that, as an observer, I can never be totally objective and judgment free. What I can do, however, is attempt to make observations without reading in my own biases and answers. Additionally, I can record my own introspection along with my interview and observational data. In my qualitative studies I accomplish this through journal writing. In my Irish study, I maintained two journals: a research journal and a personal journal. In the research journal, I recorded thoughts, feelings, experiences and anxieties more or less related to the research experience. Maintaining a personal journal is an ongoing activity in my life but one about which I am more diligent during foreign travel. When I embarked upon the research project, I had not expected my personal journal to be relevant to the research effort. But, then, I also didn't expect to be engaged in my "research" day and night either! Because of what I learned in my Irish experience, I maintained only one journal when I was conducting my research in The Netherlands.

In addition to developing self awareness about my biases, three other methods I have employed to establish reliability are consistency, triangulation and member checking. Consistency across respondents occurs when all or some group of respondents express similar views. On only a few occasions has there been complete consistency across respondents. What is more important to me is that groups of individuals represent consistent responses. When this occurs, I have greater confidence in my interpretations. Triangulation is employed to build confidence in my interpretation as well as to help me understand anomalies. One such anomaly occurred with respect to the Irish attitude toward education. I was having some difficulty in understanding the nature of responses to this question until I was able to place them in a larger context that included emigration patterns. When I did this, I could begin to see consistent responses emerging. A part of triangulation is also my participant observation. When my observations differ from what I am told in interviews, it gives me pause to consider the reason. In some cases I have been able to understand the anomaly; other times I cannot and must simply acknowledge the contradictions.

A final method for establishing reliability is member checking. Strictly speaking, this means going back to check interpretations with those who are being studied. I have employed it in a looser sense. As I discussed in the section on strangeness, since I am not of the Irish culture I am very sensitive about my perceptions of it. My interest in member checking is not so much to have the respondents agree with my perceptions as it is to have those of Ireland or more knowledgeable than me about the country evaluate my interpretations. Those from whom I have sought feedback 
include Irish studies scholars, individuals in Ireland who are not in the IT sector, and a few respondents with whom I have developed a personal relationship. My interest is in their reactions to the way I have interpreted cultural influences and impacts. In general, this has been a very affirming experience. I have had one experience, however, which raises an issue about this technique: what to do when the "members" disagree with your interpretation. This occurred with respect to a paper I wrote about women in the Irish IT sector. When I delivered the paper at an Irish studies conference, one Irish woman in the audience had a strong and negative reaction to my interpretations. Her response caused me to rethink what I had written. I went back to my transcripts and observational data and I thought again about how I reached the interpretations presented in my paper. In the end, I remained with my original interpretations. However, in the process I also discussed this experience with some of those who had witnessed it (there was a large group in attendance). In these discussions, I received help in understanding why this audience member might have reacted as she did. I also make a point of talking with this individual later in the conference. While I did not change my interpretations, the insights I gained did influence me to rephrase some aspects of them in later writings. In the Irish studies community, I have an ongoing support group that reads my work and offers critical commentary. I have found their comments to be invaluable in my efforts to establish reliability and personal confidence in my interpretations.

\section{REFERENCES}

Becker, H.,and Geer, B. (1969). "Participant Observation: A Comparison." In G. J. McCall and J. L. Simmons (Editors), Issues in Participant Observation. New York: Random House.

Ely, M.; Anzul, M.; Friedman, T.; Garner, D.; and Steinmetz, A. M. (1991). Doing Qualitative Research: Circles within Circles. New York: The Farmer Press.

Hammersley, M. (1992). What's Wrong with Ethnography? Methodological Explorations. New York: Routledge.

Hammersly, M., and Atkinson, B. (1983). Ethnography Principles in Practice. London: Tavistock Publishers, Ltd.

Harris, L. (1989). "Women's Response to Multinationals in County Mayo." In D.

Elson and R. Pearson (Editors), Women's Employment in Multinationals in Europe. London: Macmillan Press, Ltd., pp. 144-164.

Jackson, P., and Barry, U. (1989). "Women's Employment in the Republic of Ireland: The Creation of a New Female Labour Force." In D. Elson and R. Pearson (Editors), Women's Employment in Multinationals in Europe. London: Macmillan Press, Ltd., pp. 38-59.

Jick, T. (1979). "Mixing Qualitative and Quantitative Methods: Triangulation in Action." Administrative Science Quarterly, Volume 24, Number 4, pp. 602-611. 
Jorgensen, D. L. (1989). Participant Observation: A Methodology for Human Studies. Newbury Park, California: Sage Publications.

Lincoln, Y., and Guba, E. (1985). Naturalistic Inquiry. Beverly Hills, California: Sage Publications.

Strauss, A. L. (1987). Qualitative Analysis for Social Scientists. New York: Cambridge University Press.

Trauth, E. M. (1993). "Educating Information Technology Professionals for Work in Ireland: An Emerging Post-industrial Country." In M. Khosrowpour and K. Loch (Editors), Global Information Technology Education: Issues and Trends. Harrisburg, Pennsylvania: Idea Publishing Co., pp. 205-233.

Trauth, E. M. (1995). "Women in Ireland's Information Industry: Voices from Inside." Eire-Ireland, Volume 30, Number 3 (Fall), pp. 133-150.

Trauth, E. M. (1996a). "Issues with Ethnographic Research across Cultures: The Dilemma of Staying 'Strange' during Participant Observation." Annual Meeting of the American Conference on Irish Studies, Carbondale, Illinois. April.

Trauth, E. M. (1996b). "Societal Impact of an Imported IT Sector on Newly Industrializing Countries: Lessons from Ireland." In E. M. Roche and M. J. Blaine (Editors), Information Technology Development and Policy: Theoretical Perspectives and Practical Challenges. Aldershot, United Kingdom: Ashgate Publishing Ltd., pp. 245-261.

Trauth, E. M.; Derksen, F. E.; and Mevissen, H. M. (1993). "The Influence of Societal Factors on the Diffusion of Electronic Data Interchange in the Netherlands." In D. Avison, J. Kendall and J. I. DeGross (Editors), Information Systems Development: Human, Social and Organizational Aspects. Amsterdam: NorthHolland.

Trauth, E. M.; Farwell, D.; and Lee, D. M. S. (1993). "The IS Expectation Gap: Industry Expectations versus Academic Preparation." MIS Quarterly, Volume 17, Number 3 (September), pp. 293-307.

Trauth, E. M., and O'Connor, B. (1991). “A Study of the Interaction between Information Technology and Society: An Illustration of Combined Qualitative Research Methods." In H-E. Nissen, H. K. Klein, and R. Hirschheim (Editors), Information Systems Research: Contemporary Approaches and Emergent Traditions. Amsterdam: North-Holland, pp. 131-144.

Yin, R. K. (1989). Case Study Research: Design and Methods. Newbury Park, California: Sage Publications.

\section{BIOGRAPHY}

Eileen M. Trauth is an Associate Professor of Information Systems in the Management Science Group of the College of Business Administration at Northeastern University. Her teaching and research interests include the societal, organizational 
and educational impacts of information technology, information management, national information policy issues, and global informatics. Her articles have appeared in numerous journals as well as several proceedings for the International Federation for Information Processing. She has published a textbook entitled Information Literacy: An Introduction to Information Processing and is completing work on a book about an ethnographic study of an emerging information economy. She has been a visiting professor in several countries, including Ireland where she was a Fulbright Scholar. Professor Trauth is a member of the Society for Information Management, the International Federation for Information Processing, and the Information Resources Management Association. Professor Trauth received her Ph.D. in Information Science from the University of Pittsburgh. 